\title{
Directional Avoidance Turns Encoded by Single Interneurons and Sustained by Multifunctional Serotonergic Cells
}

\author{
Jian Jing and Rhanor Gillette \\ Department of Molecular and Integrative Physiology and the Neuroscience Program, University of Illinois, Urbana, Illinois 61801
}

Avoidance turns in the sea slug Pleurobranchaea are responses to noxious stimuli and replace orienting turns to food stimuli after avoidance conditioning or satiation. Avoidance turns proved to be centrally patterned behaviors, the fictive expression of which could be elicited in reduced preparations and the isolated CNS. Activity in one of a bilateral interneuron pair, the A4 cells, was necessary and sufficient to drive the avoidance turn toward the contralateral side. Single A4 cells appeared to encode both turn direction and angle, in contrast to directional behaviors of other animals in which displacement angle is usually encoded by multiple units.

The As1- 4 cells, bilateral serotonergic cell clusters, excited the prolonged A4 burst during the turn through electrical and chemical coupling. However, during the escape swim, As1-4 became integral elements of the swim motor network, and A4 activity was entrained to the swim rhythm by alternating excitatory-inhibitory inputs, with only weak spiking. This provides a likely mechanism for the previously observed suppression of the avoidance turn by escape swimming. These observations add significant new aspects to the multiplying known functions of As1-4 and their homologs in other molluscs and point to a pivotal role of these neurons in the organization of gastropod behavior.

Simple functional models predict (1) the essential actions of inhibitor neurons in the directionality of the turning network motor output and (2) an integrating role for As1- 4 in the behavioral switch between turning avoidance and swimming escape, on the basis of their response to increasing stimulus intensity.

Key words: Pleurobranchaea; orienting and avoidance turns; directional behavior; population coding; escape swimming; central pattern generator; mollusc; premotor neurons; avoidance behavior; behavioral decision

\section{Introduction}

Active animals may either orient to or avoid salient stimuli in the environment, depending on stimulus modality and strength, internal state, and experience. The decision-making mechanisms that direct orienting or avoidance are basic to foraging and reproductive strategies and for avoidance of unnecessary risk from predation and self-injury. The premotor network systems that mediate directional turning can be expected to provide relatively simple model systems for addressing how sensation, appetite, and experience are integrated at the level of the neural network. Specifically, understanding of network structure and function can be used to address how the animal decides to make either orienting or avoidance turns and how direction and amplitude of those turns are computed.

Directional turning in the predatory sea slug Pleurobranchaea californica differs markedly in its nature, depending on whether the animal responds to appetitive or aversive stimuli. Orienting turns are goal directed, tend to be relatively precise, and are corrected continuously by appetitive sensory input, enabling eventual localization of the stimulus source. In contrast, the avoidance

\footnotetext{
Received Aug. 27, 2002; revised Jan. 14, 2003; accepted Jan. 17, 2003.

This research was supported by National Science Foundation Grant IBN-9808400 and National Institute of Mental Health Grant MH59339. We thank Drs. Ralph DiCaprio and Kurt Potgieter for assistance in data analysis.

Correspondence should be addressed to Jian Jing, Department of Physiology and Biophysics, Box 1218, Mount Sinai School of Medicine, One Gustave L. Levy Place, New York, NY 10029-6574. E-mail: jjing@inka.mssm.edu. Copyright $\odot 2003$ Society for Neuroscience $\quad 0270-6474 / 03 / 233039-13 \$ 15.00 / 0$
}

turn is stereotypic in nature and resembles a classic fixed action pattern in its triggerability and episodic nature. Avoidance turns also differ from orienting turns in their coarse nature, generally involving angles of $30-250^{\circ}$, which are sufficient to redirect the animal's locomotion clearly away from the stimulus.

Turning responses to both appetitive and noxious stimuli in Pleurobranchaea, as for animals with more complex CNS, are modifiable through associative learning (Mpitsos and Collins, 1975) and changing hunger state (Gillette et al., 2000). Specifically, avoidance turns replace orienting turns to food stimuli after avoidance conditioning or satiation. To elucidate the decisionmaking processes that choose among avoidance turns and alternative behaviors, we have studied neuronal mechanisms that mediate the avoidance turn.

By describing the distribution and innervation of muscles mediating turning behavior as well as fictive avoidance turning motor output, we were able to identify a pair of premotor neurons, the A4 cells, in the cerebropleural ganglion that individually commanded the avoidance turn. Their apparent ability to encode both turn direction and amplitude is novel for single neurons (see Discussion for a comparison with other systems). A bilaterally paired serotonergic interneuron group, the As1-4, found previously to have dual roles in the centrally patterned genesis of escape swimming behavior and in general behavioral arousal (Jing and Gillette, 1999, 2000), sustained A4 activity through electrical and chemical excitation. These results add further dimension to the multifunctionality of the As1-4 neurons and emphasize their 
prominence in the organization of the animal's behavior. Simple functional models outline the structure of the avoidance turn network and its interaction with the escape swimming network.

Preliminary reports have been published previously (Jing and Gillette, 1996; Jing, 1998).

\section{Materials and Methods}

Specimens of Pleurobranchaea californica (3-600 gm) were obtained from Sea-Life Supply (Sand City, CA) and Pacific BioMarine (Santa Monica, CA) and kept in circulated artificial seawater at $14^{\circ} \mathrm{C}$ until use.

Gross anatomy: muscle distribution and nerve innervation. Animals were anesthetized by isotonic $\mathrm{MgCl}_{2}$ injection ( $30-50 \%$ body volume). Viscerae were removed through a dorsal or ventral cut, and the remaining body with ganglia was bathed in $50 \%$ isotonic $\mathrm{MgCl}_{2}$ in seawater at $4^{\circ} \mathrm{C}$ for $\geq 2 \mathrm{hr}$. In some preparations, the bathing solution was replaced with $3-10 \%$ buffered formalin in isotonic $\mathrm{MgCl}_{2}$ for fixation.

The distribution of superficial nerves and muscles was drawn, and then they were carefully cut away to expose underlying structure. The attachments and directional orientation of muscle bands were especially noted, and the sites where nerve branches entered the muscles were described.

Intact animals: videotaping the behavior and nerve lesion. When observing the animal's turning behavior, the animal was placed on the side of the tank, and the animal's foot or its back was videotaped during actual behavior. Avoidance turning was induced by shocking unilaterally the animal's oral veil for $1-2 \mathrm{sec}(10-40 \mathrm{~V}, 20 \mathrm{~Hz}, 10 \mathrm{msec}$ duration; delivered by a bipolar 20 gauge chlorided silver wire electrode with $1 \mathrm{~mm}$ exposed tips $2 \mathrm{~cm}$ apart). Avoidance turn episodes were digitized (25 frames per second) for frame-by-frame analysis of body position and turn angle (compare Fig. 2).

For lesion experiments, animals were first anesthetized by injection of $30-50 \%$ of the body volume of isotonic $\mathrm{MgCl}_{2}$ (filtered with a $0.22 \mu \mathrm{m}$ syringe filter). A longitudinal dorsal incision of $1-2 \mathrm{~cm}$ was made between the rhinophores. The pedal or cerebropleural nerves of interests were exposed and cut. Care was taken to avoid loss of body fluid. The dorsal incision was then sutured shut with sterile surgical suture (5-O for small animals, 4-O for large animals), and the animal was returned to a tank of circulated artificial seawater for recovery. To improve recovery, $10-30 \%$ of body volume of filtered fresh artificial sea water was injected into the animal every $1-2 \mathrm{hr}$ two to three times after the surgery. Typically, animals recovered in $24 \mathrm{hr}$ and resumed normal-seeming locomotion and other activity.

Whole animals, isolated CNS, and reduced preparations. Dissections were made under cold anesthesia at $4^{\circ} \mathrm{C}$. Whole animal preparations, isolated nervous systems, and reduced (hemi-animal) preparations were as described previously (London and Gillette, 1984; Jing and Gillette, 1995). Whole animal preparations were made by accessing the cerebropleural ganglion through a $2 \mathrm{~cm}$ dorsal incision and pinning it to a wax platform. Hooks retracting the incision partially supported and restrained the animal for stable intracellular recordings but left it capable of considerable movement, including turning and vigorous swimming and feeding behavior. The preparation chamber was constantly perfused with fresh artificial seawater $\left(14^{\circ} \mathrm{C}\right)$. Isolated CNS preparations included cerebropleural and pedal ganglia and buccal ganglion and were pinned to Sylgard, under saline at $14^{\circ} \mathrm{C}$, of composition (in mM): $420 \mathrm{NaCl}, 10 \mathrm{KCl}$, $25 \mathrm{MgCl}_{2}, 25 \mathrm{MgSO}_{4}, 10 \mathrm{CaCl}_{2}$, and $10 \mathrm{MOPS}$ buffer, adjusted to $\mathrm{pH} 7.5$ with $\mathrm{NaOH}$. A reduced preparation comprised the head (oral veil, tentacle, rhinophore, and sometimes mouth) and the CNS with cerebropleural nerves intact. These structures were then pinned on a Sylgard dish with two connected chambers for CNS and head for electrical recording and stimulation of head sensory organs. Fictive avoidance turning was induced with a similar stimulation protocol as for intact animals. For stimulating fictive turning or swimming in the isolated CNS, monopolar shocks of $2 \mathrm{msec}$ in duration, $1-5 \mathrm{~V}, 15 \mathrm{~Hz}$, for $1-2 \mathrm{sec}$, were delivered to nerves through suction electrodes.

Intracellular and extracellular recordings were done with conventional $\mathrm{KCl}$-filled glass micropipettes and polyethylene suction electrodes as described previously (Jing and Gillette, 1995). Data were recorded on a chart recorder (Gould TA11; sampling rate, $250 \mathrm{kHz}$ ) and on a video tape recorder.

Functional synaptic connections were examined in normal saline for PSP ability to follow presynaptic spikes one-for-one as a criterion of probable monosynapticity. Assays of probable monosynapticity or polysynapticity were also conducted in high-divalent saline (in mM): 240 $\mathrm{NaCl}, 10 \mathrm{KCl}, 125 \mathrm{MgCl}_{2}, 25 \mathrm{MgSO}_{4}, 30 \mathrm{CaCl}_{2}$, and $10 \mathrm{MOPS}$ to elevate spike thresholds and curtail polysynaptic activation.

Electrical coupling was assayed by passage of hyperpolarizing current into one cell and measuring steady-state polarization in its partner. The steady-state coupling coefficient was taken as the ratio of postsynaptic to presynaptic voltage change.

Data analysis. Taped data of intracellular recordings were later plotted for measures of resting potential and spike height and duration (at half amplitude). Spike height measures were taken when cells were spontaneously active at only low rates to avoid use-dependent attenuation.

To quantify the turning motor output in bilateral motor nerves (see Fig. 3), the spike events in extracellular recordings were counted over time using peak detection by commercial software, and the mean spike frequency was plotted. Mean spike frequency was calculated in bins of 1 sec and results were plotted in spikes per second.

Cell identification and intracellular staining. The A cluster neurons are located on the dorsal side of the cerebropleural ganglion near the root of the rhinophore nerve (Jing and Gillette, 1995, 1999). The cells As2 and As 3 are indistinguishable and are referred to here singly as As2/3, as previously. Elements of the central pattern generator (CPG) for escape swimming were identified from their electrophysiology and circuitry connections as described in the previous report (Jing and Gillette, 1999). The neurons A4 and A7 are newly described here (see Table 2).

Neuron morphology was studied by iontophoretic or pressure injection with biocytin (Sigma, St. Louis, MO) or neurobiotin (Vector, Burlingame, CA) from the recording electrode as described previously (Jing and Gillette, 1995). After an incubation of varying period, tissues were fixed, and the stain was developed and viewed in cleared whole mounts. Pressure injection of somata allowed staining of axon processes up to 2 $\mathrm{cm}$ from the injection site after ganglia were incubated overnight at $8^{\circ} \mathrm{C}$.

\section{Results}

Turning toward or away from a stimulus in Pleurobranchaea is effected through asymmetrical contraction of longitudinal lateral body wall and foot muscles. Thus, an orienting turn is achieved through contraction of muscle ipsilateral to the stimulus, whereas avoidance is done by contralateral muscle contraction. To analyze the neural circuitry of turning, we described the anatomy and innervation of the muscles likely to be involved and assessed their functional roles in lesion experiments. We then characterized motor nerve activity during fictive avoidance turning and used that activity as an indicator to identify putative premotor turning neurons coactive during the turning response.

\section{Functional anatomy of turning: muscle distribution and innervation}

Longitudinal muscles of the body wall and foot

The lateral body wall muscle (LBWM) lies prominently on the internal surface of the lateral body wall, just dorsal to the edge of the foot. It is formed of three strap-like muscle bands that begin anteriorly and join posteriorly as shown (Fig. 1, Table 1). The LBWM is connected to the body wall along its entire length, such that contraction compresses and folds the external skin. The most medial band (band A) originates anteriorly at the oral tube and ventral part of the mouth, oral veil, and ventral tentacle. The next band (band B) originates in the lateral region of oral veil, mouth, dorsal tentacle, and base of the rhinophore. The most lateral band (band C) originates at the dorsal region of the oral veil, mouth, and oral tube and buccal mass. 


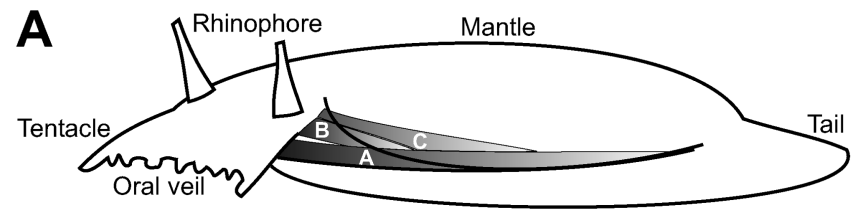

B

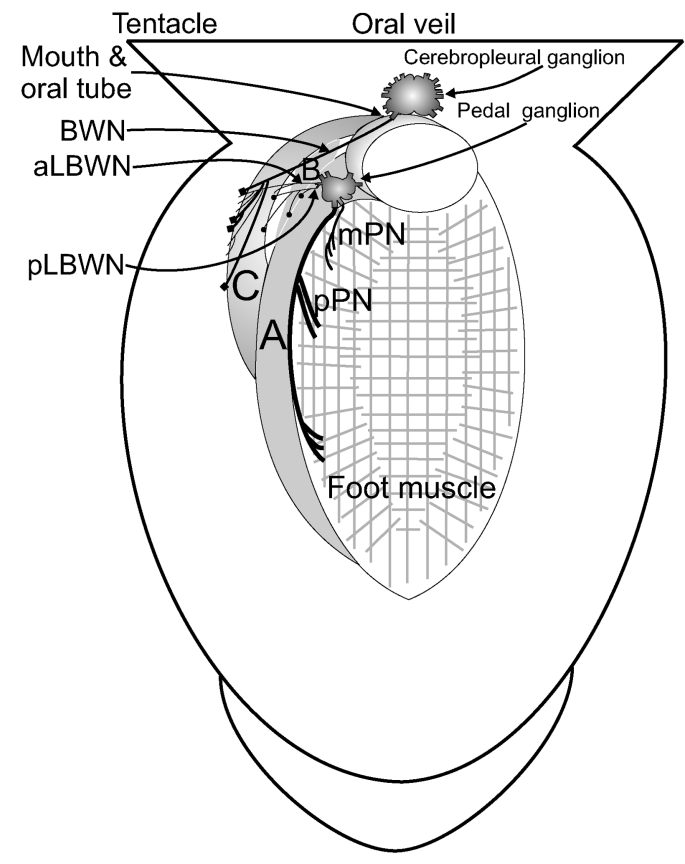

Figure 1. The lateral body wall muscles (LBWM). $A$, Schematic drawing of the position of the LBWM viewed from the left side of an intact animal. $B$, Distribution of muscle bands and nerve innervation in dorsal view in a dissected preparation. Lateral body wall muscles are shown on the left. The LBWM of the right side is generally similar, with slight asymmetry caused by the presence of reproductive organs, anus, and heart (data not shown). The muscle bands $A, B$, and Cof LBWM are shown, as are the large fascicles of the LMF and the circular muscles of the foot. The major innervation of LBWM is from the posterior lateral body wall nerve ( $p L B W N$ ) of the pedal ganglion. Other innervation comes from the anterior lateral body wall nerve ( $a L B W N$ ) of the pedal ganglion and the body wall nerve (BWN) of the cerebropleural ganglion. Foot muscles and pedal cilia are innervated by the medial pedal nerve ( $M P N)$, posterior pedal nerve ( $p P N)$, and anterior pedal nerve ( $a P N$ ) [which goes below the branch A1 of band A of LBWM (Table 1) to innervate the foot there; data not shown] of the pedal ganglion.

According to Brace (1977a,b), this muscle may originate from the lateral columellar muscle (LCM) attached to the external or internal shell present in most other gastropods. The name LCM has been used for the analogous muscle of Aplysia (Cook and Carew, 1989; Kuenzi and Carew, 1994), which has also been called the lateral longitudinal muscle (Bablanian et al., 1987). In Aplysia, this muscle mediates the horizontal component of headwaving behavior (Cook and Carew, 1989; Kuenzi and Carew, 1994) and may also mediate, at least partially, appetitive head turning (Teyke et al., 1990) and directional defensive responses (Walters and Erickson, 1986).

Additional longitudinal muscles of a large fascicle type can also be observed along the body wall. Other body wall muscle fibers lie dorsally as well as externally to the LBWM in small bundles oriented helically, longitudinally, and circularly. The longitudinal muscles of the foot (LMF) lie in large fascicles interwoven with circular and helical muscles.

Innervation of the muscles

The longitudinal muscles described above are innervated by bilaterally symmetrical nerves from the pedal and cerebropleural ganglia (Fig. 1, Table 1) (see Fig. $4 A$ for relevant CNS anatomy). The LBWM is divisible into two functional parts related to its distribution and innervation. (1) Those major portions of the LBWM that appear to mediate the lateral flexion prominent in avoidance turns receive most innervation from the posterior lateral body wall nerve (pLBWN), as well as some branches from the anterior LBWN (aLBWN) and possibly from the body wall nerve (BWN) (because aLBWN and BWN anastomose). The pLBWN from the right pedal ganglion also sends a major branch to the genital ganglion, termed the pedal-genital connective (PGC) (Table 1). (2) The anterior LBWM terminates in all head regions associated with food chemosensation and feeding, including oral veil, tentacle, and rhinophore, and the feeding motor areas including the mouth, oral tube, and base of the buccal mass, consistent with roles in head posture and movement during feeding. These anterior portions of the LBWM are innervated by pedal nerve 2 (P2) (Lee and Liegeois, 1974), the mouth nerve, and to a lesser extent by the large and small oral veil nerves (LOVNs and SOVNs). Body wall muscles dorsal to LBWM are primarily innervated by aLBWN and BWN.

The anterior, medial, and posterior portions of the muscles of the foot are innervated by the anterior, medial and posterior pedal nerves (aPNs, mPNs, and pPNs), respectively.

\section{Neural correlates of avoidance turning}

The avoidance turn

Avoidance turning can be reliably elicited in intact animals by electrically shocking the oral veil or tentacles unilaterally (Fig. 2). Such turns are indistinguishable from those caused by naturally noxious and avoidance-conditioned stimuli (Mpitsos and Davis, 1973; Gillette et al., 1991). It is a stereotypic behavior observed in at least five notaspid opisthobranch species (Gillette et al., 1991). After stimulation, forward locomotion is suppressed and the head is withdrawn. Beginning the turn, the anterior part of the foot is lifted slightly off the substrate while the animal flexes right or left $45-250^{\circ}$ away from the stimulus, pivoting on its broadened posterior foot/tail region, which remains attached to the substrate. In seven animals, the turn was completed on average within $34 \pm 1.4 \mathrm{sec}$, from turn initiation to the beginning of locomotion, when the anterior foot region reattached to the substrate and forward locomotion commenced (Fig. 2). At the end of the turn and beginning of locomotion, the tail narrowed to a sharper tip and was frequently detached from the substrate. In contrast to the avoidance turn, orienting turning did not interrupt locomotion and was more variable in amplitude of turning angles.

\section{Nerve lesion experiments}

We lesioned nerves to examine the functional roles of the LBWM and LMF, and of their nerves, in avoidance turning. Avoidance turning was induced by unilateral application of an electrical shock to the oral veil and tentacle region. Effects of shock on the avoidance turn were compared before and after lesions. Neither single nor incomplete combinations of unilateral lesions of aLBWN, pLBWN, and BWN or aPN, mPN, and pPN completely eliminated turning behavior; complete elimination required lesion of all six nerves $(n=5)$. Thus, all of the longitudinal muscles of the body wall and the foot may contribute to turning. Lesioning of the pedal nerves $(\mathrm{aPN}, \mathrm{mPN}$, and $\mathrm{pPN})$ also eliminated ciliary movement on the lesioned side of the foot, indicating that the pedal nerves mediate ciliary movements as well contribute to turns $(n=3)$. 
Table 1. LBWM subdivisions and domains

\begin{tabular}{|c|c|c|c|c|c|c|}
\hline Name and location & Morphology and distribu & & $\begin{array}{l}\text { Termination in the head } \\
\text { region }\end{array}$ & Likely functions & Innervation & Other names \\
\hline \multirow[t]{2}{*}{$\begin{array}{l}\text { Band A: most } \\
\text { ventral }\end{array}$} & \multirow[t]{3}{*}{$\begin{array}{l}\text { The branch A1 splits } \\
\text { from band A in the } \\
\text { head region; band A } \\
\text { courses anteriorly }\end{array}$} & Band A & $\begin{array}{l}\text { (1) Ventral head structures: } \\
\text { ventral part of the } \\
\text { mouth, the oral veil, } \\
\text { and ventral tentacle }\end{array}$ & $\begin{array}{l}\text { Head turning, oral } \\
\text { veil, and tentacle } \\
\text { movements }\end{array}$ & pLBWN & None \\
\hline & & \multirow[t]{2}{*}{$\begin{array}{l}\text { Branch A1, after } \\
\text { detaching, muscles } \\
\text { fascicles become flatter } \\
\text { and wider }\end{array}$} & $\begin{array}{l}\text { Most caudal end of ventral } \\
\text { and lateral oral tube, } \\
\text { just anterior to the } \\
\text { buccal mass }\end{array}$ & $\begin{array}{c}\text { Proboscis retraction, } \\
\text { mouth opening }\end{array}$ & Mouth nerve & $\begin{array}{l}\text { Muscle } 3 \text { (Davis et al., } \\
\text { 1973); muscle } 23 \\
\text { (Lee and Liegeois, } \\
\text { 1974) }\end{array}$ \\
\hline $\begin{array}{l}\text { Band } B \text { : dorsal to } \\
\text { band } A\end{array}$ & & & $\begin{array}{l}\text { (2) Lateral head structures: } \\
\text { lateral part of the oral } \\
\text { veil, the mouth; the } \\
\text { base of the rhinophore; } \\
\text { and dorsal (caudal) } \\
\text { tentacle }\end{array}$ & $\begin{array}{l}\text { Head movement, } \\
\text { and turns }\end{array}$ & $\begin{array}{l}\text { Anterior region: nerve } \\
\text { branches from P2; } \\
\text { posterior region: } \\
\text { branches from } \\
\text { pLBWN (left), PGC } \\
\text { (right) }\end{array}$ & None \\
\hline \multirow[t]{4}{*}{$\begin{array}{l}\text { Band } C \text { : dorsal to } \\
\text { band B }\end{array}$} & \multirow{4}{*}{$\begin{array}{l}\text { As the muscles course } \\
\text { toward the head } \\
\text { region, three } \\
\text { branches detach: the } \\
\text { first one is branch } \\
\text { C1, the second is } \\
\text { branch C2, and the } \\
\text { third is branch C3 }\end{array}$} & Band C & $\begin{array}{l}\text { (3) Dorsal head structures: } \\
\text { dorsal part of the oral } \\
\text { veil, the mouth }\end{array}$ & $\begin{array}{l}\text { Head, mouth } \\
\text { movements }\end{array}$ & $\begin{array}{l}\text { Nerve branches from } \\
\text { aLBWN, pLBWN } \\
\text { (PGC), maybe } \\
\text { BWN also }\end{array}$ & $\begin{array}{c}\text { See muscle } 30 \text { (Lee and } \\
\text { Liegeois, 1974) }\end{array}$ \\
\hline & & $\begin{array}{l}\text { Branch (1, flat and wide } \\
\text { (small portions of it } \\
\text { come off from band B) }\end{array}$ & $\begin{array}{l}\text { Caudal end of the dorsal } \\
\text { oral tube }\end{array}$ & $\begin{array}{l}\text { Proboscis extension } \\
\text { and withdrawal } \\
\text { (feeding) }\end{array}$ & (LOVN) & $\begin{array}{l}\text { Muscle } 29 \text { or } 28 \text { (Lee } \\
\text { and Liegeois, 1974) }\end{array}$ \\
\hline & & $\begin{array}{l}\text { Branch } \mathrm{C}_{2} \text {, the point it } \\
\text { detaches is medial to } \\
\text { the eye }\end{array}$ & $\begin{array}{l}\text { Anterior region of the } \\
\text { dorsal buccal mass }\end{array}$ & $\begin{array}{l}\text { Withdrawal of the } \\
\text { buccal mass } \\
\text { (feeding) }\end{array}$ & (SOVN) & $\begin{array}{l}\text { Muscle } 2 \text { (Davis et al., } \\
\text { 1973); muscle } 22 \\
\text { (Lee and Liegeois, } \\
\text { 1974) }\end{array}$ \\
\hline & & Branch C3, flat and wide & $\begin{array}{l}\text { Rostral end of the ventral } \\
\text { oral tube and the mouth }\end{array}$ & & & $\begin{array}{l}\text { None, but see muscle } \\
32 \text { (Lee and } \\
\text { Liegeois, 1974) }\end{array}$ \\
\hline
\end{tabular}
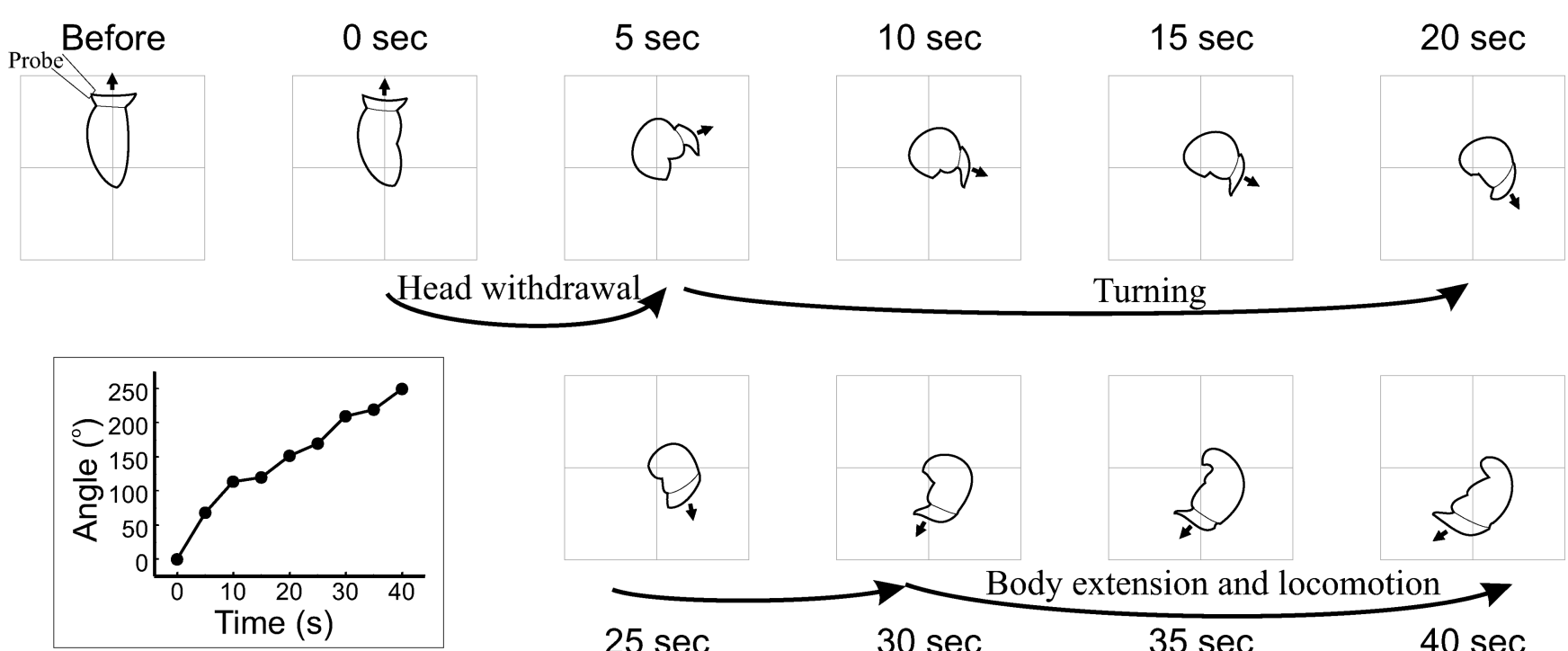

$25 \mathrm{sec}$

$30 \mathrm{sec}$

$35 \mathrm{sec}$

$40 \mathrm{sec}$

Figure 2. The progression of the avoidance turn of a living animal, viewed dorsally. Drawings were from video frames of the avoidance turn to the right side induced by electric shock (Probe) to the left oral veil. Initial responses were head withdrawal, body shortening, and turn initiation. At $\sim 30 \mathrm{sec}$, the animal extended its body and locomoted away from the stimulus. The tail, which remained attached to substrate, did not change position during the actual turning phase. Arrows show direction faced by the animal, based on extension of a line joined by midpoints of oral veil and neck. Inset, Plot of turn angle versus time relative to the initial direction of the animal.

Fictive avoidance turning in reduced preparations and isolated CNS

We recorded fictive avoidance turning motor activity in the nerves of reduced preparations of head and attached CNS. Electrical shock was applied to the head while motor output was recorded from the cut nerves. Among the nerves examined, the pLBWNs showed the most prominent, directionally specific ac- tivity expected of fictive avoidance turning (Fig. 3$)(n=8)$, and these nerves were therefore used in subsequent experiments to monitor turning motor activity.

The motor activity in pLBWN had two components: (1) an early burst of activity lasting $<5 \mathrm{sec}$ of similar intensity in both right and left nerves, accompanied by local head and oral veil contraction in the reduced preparation. This response was of 
A. Shock left oral veil

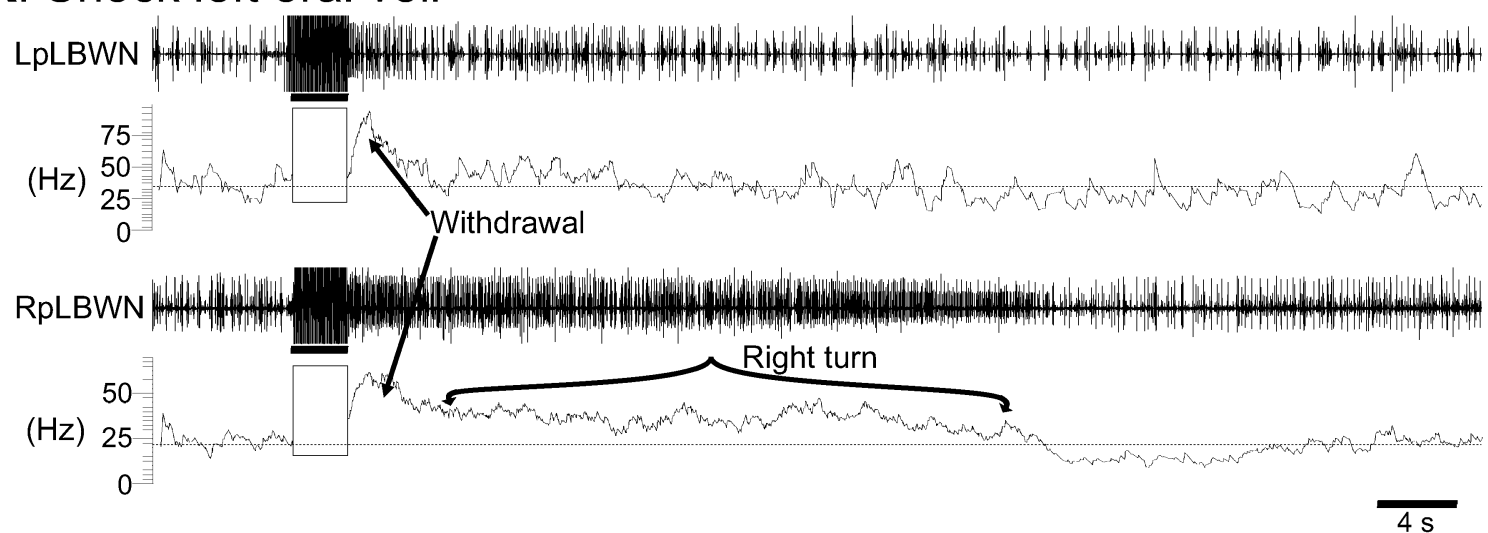

\section{B. Shock right oral veil}

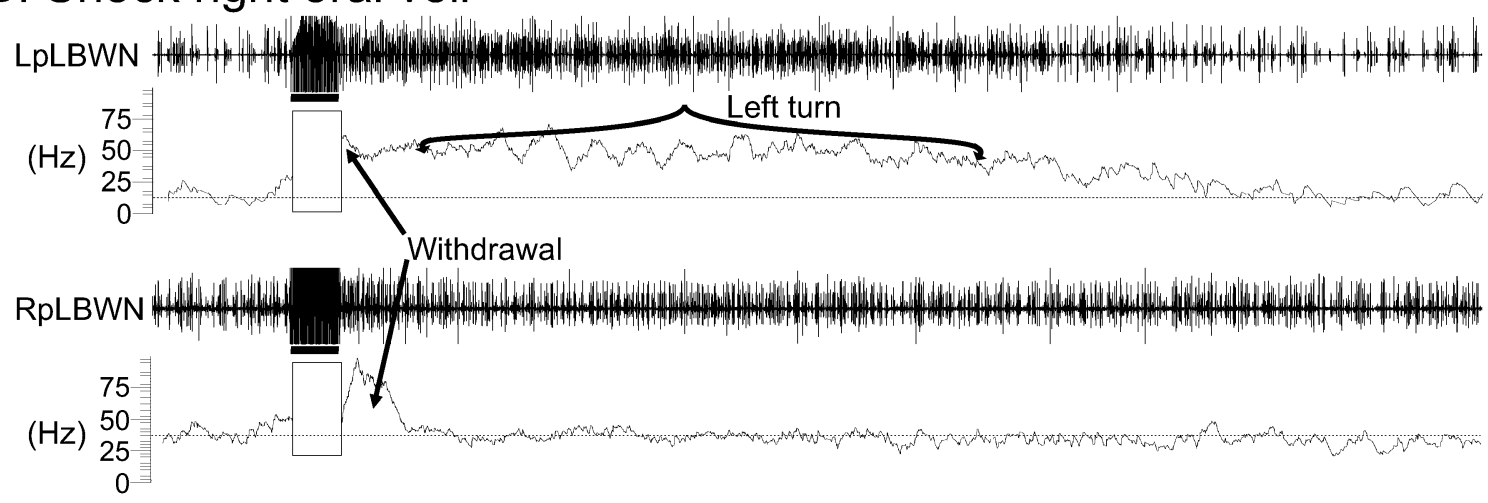

Figure 3. The posterior lateral body wall nerve shows directionally specific motor activity after unilateral shock (bars) to the head region in a reduced preparation. Initial activity ( $<5$ sec), presumed to represent head withdrawal, is present in both nerves. Subsequent activity is greatest in the nerve contralateral to the shock application, consistent with fictive avoidance turning. $A$, Shock to left side. $B$, Shock to right side. Mean spike frequency is plotted below the nerve recordings (bin size $1 \mathrm{sec}$; see Materials and Methods); dotted lines are baseline frequency. Vertical rectangles indicate stimulation interval. LpLBWN, Left pLBWN; RpLBWN, right pLBWN.

appropriate time course to correspond to head withdrawal in the intact animal. (2) A later component exhibited most prominent activity in the nerve contralateral to the stimulus, which lasted several tens of seconds and was temporally consistent with the avoidance turn.

Subsequently, we found that similar, unilaterally specific activity occurred in pLBWNs of the completely isolated CNS ( $n=$ 16) (compare Figs. 5, 9) in response to shock of either of the bilateral LOVN innervating the oral veil. The LOVN carries mechanosensory information from the oral veil to the brain (Kovac and Davis, 1980). Tentacle and rhinophore nerves were less effective in inducing directionally specific activity in pLBWN. Shock thresholds for avoidance turns, for the electrodes used, lay between 1 and $5 \mathrm{~V}$. Lower intensity shocks elicited only weak activity in pLBWN, whereas shock intensities $>5 \mathrm{~V}$ caused strong and prolonged spike activity in bilateral pLBWN and occasionally the cyclic bursting of fictive escape swimming.

\section{Turning premotor neurons}

To find premotor neurons that mediate the turning behavior, we surveyed neurons in the A cluster of the cerebropleural ganglion (Fig. 4A). The A cluster is a group of interneuron cell bodies that mostly project to the pedal ganglion (Jing and Gillette, 1995, 1999), from which the turn muscles are innervated. The A cluster contains elements of the CPG for escape swimming and other interneurons connected with the CPG that interact with the feed- ing and other motor networks (Fig. 4A) (Jing and Gillette, 1999, 2000). The summary model of Figure 14 may be consulted on the functional identities of the neurons discussed here. We looked for possible avoidance turning premotor neurons while observing cell responses to aversive electrical shock applied to one side of the oral veil in the reduced preparation and to stimulation of LOVN in the isolated CNS.

\section{Directionally specific activity of A4 and As1-3}

Among the A cluster, we found five neurons with responses to LOVN stimulation that corresponded well to the turning motor output. These neurons were the newly characterized A4 and the previously identified serotonergic As1-4 cells (Fig. 4A) (Jing and Gillette, 1999). Alone of all A cluster cells, the A4 cells showed strong and directionally specific activity in a prolonged burst closely corresponding to the fictive avoidance turn (Fig. 5A) $(n=$ 11). For 2-6 sec after the shock stimulus, prolonged tonic firing (13-17 Hz) occurred for tens of seconds in the A4 ipsilateral, but not contralateral, to the stimulus.

In some preparations, as shown in Figure 5A2, after the avoidance turn period, a slow rhythm of spontaneous activities in the bilateral A4 cells began to occur in anti-phase to each other, perhaps representing frequent spontaneous left/right turning as has been occasionally observed in intact animals after avoidance turns (our unpublished observations). A4 proved to be difficult to hold while recording avoidance turns in whole animal prepa- 

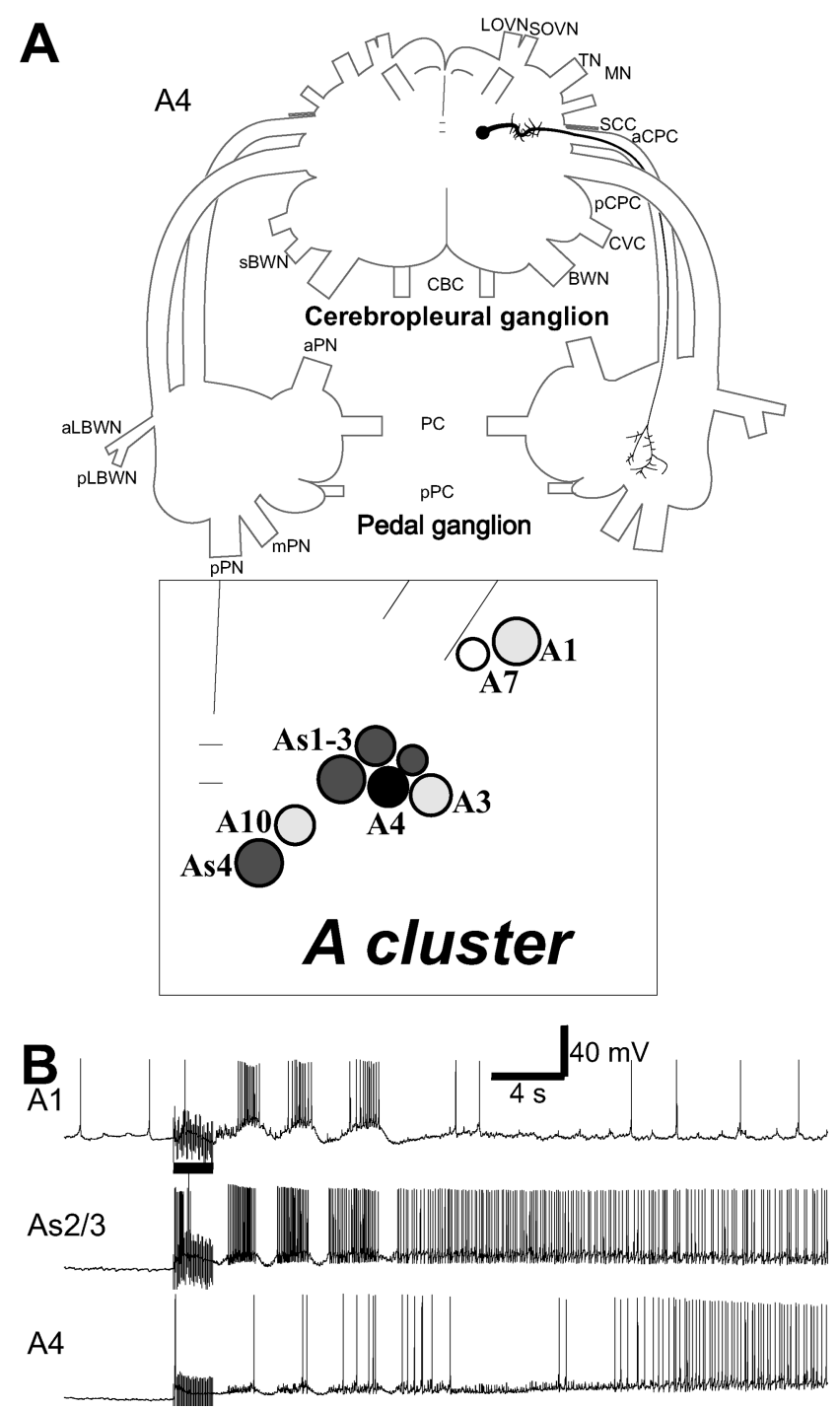

Figure 4. Relative location and morphology of $\mathrm{A} 4$ and its activity during a fictive swim. $A$, The axon of $A 4$ courses laterally to the ipsilateral $A C P C$, branching in the cerebropleural neuropile before entering the connective $(n=9)$. The axon enters the pedal ganglion to branch there in the neuropil. Inset, Locations of the interneurons in the A cluster (dorsal surface). Somata are shown only unilaterally for convenience. Cerebropleural ganglion: $B W N$, body wall nerve; $S B W N$, small body wall nerve; $C B C$, cerebrobuccal connective; $A C P C$, anterior cerebropedal connective; $P C P C$, posterior cerebropedal connective; $C V C$, cerebrovisceral connective; $L O V N$, large oral veil nerve; $M N$, mouth nerve; $R N$, rhinophore nerve; $S C C$, subcerebral commissure; $S O V N$, small oral veil nerve; $T N$, tentacle nerve. Pedal ganglion: $a L B W N$, anterior lateral body wall nerve; $p L B W N$, posterior lateral body wall nerve; $P C$, pedal commissure; $P P C$, parapedal commissure; $a P N$, anterior pedal nerve; $m P N$, medial pedal nerve; $P P N$, posterior pedal nerve. $B, A 4$ (bottom) was weakly active during escape swimming elicited by BWN stimulation (bar). The membrane potential of A4 oscillated in phase with As2/3 (middle), the activity of which led slightly that of the A1 swim interneuron (top).

rations; however, two such recordings were successfully made in which spike activity similar to fictive avoidance turns was observed (Fig. 5B).

As1-3 cells, the serotonergic swim interneurons, were also activated during and after the avoidance turning phase (Fig. 6). The As1-3 groups of both sides of the brain were sensitive to laterality of the shock, with the cells ipsilateral to the stimulus showing higher activity. In six experiments, average spike frequencies for As $2 / 3$ responses to ipsilateral shock were $7.3 \mathrm{~Hz}$, whereas contralateral responses were $3.5 \mathrm{~Hz}$. For As1, ispilateral responses were $3.5 \mathrm{~Hz}$ versus $2.5 \mathrm{~Hz}$ for contralateral responses $(n=3)$. The latencies of As1-3 responses to stimuli were shorter for ipsilateral than for contralateral cells.

Other neurons in the A cluster either showed little response to LOVN stimulation (A1, A10, A3) or their responses did not correspond well to fictive turning motor output (A7) (Table 2). These cells are not addressed further here except for their connectivity with A4.

\section{Anatomy and electrophysiology of A4}

The anatomy and much of the synaptic connectivity of As1-4 have been described previously (Jing and Gillette, 1999). The soma of A4 lies next to the somata of As1-3 and A3 (Fig. 4A), which it resembles in color and size. The single axon of A4 projects to the ipsilateral pedal ganglion through the anterior cerebropedal connective (Fig. 4A, Table 2), in contrast to most other neurons in the A cluster, which project contralaterally.

A4 is synaptically driven by neurons of the escape swim CPG but is not a part of the CPG. During fictive escape swims, the membrane potential of A4 oscillated in phase with that of As1-3 (Fig. 4B) (26 observations in 18 preparations), sometimes firing spikes during the depolarized phase (in 15 of 26 observations). A4 spike activity varied with swim intensity, being less active during weaker swims and building slightly in intensity over multiple cycles. The duration and activity phases of these later bursts matched those of As $2 / 3$. There were no detectable effects of hyperpolarizing a single A4 neuron on the escape swim $(n=5)$.

A4 made strong connections to As1-4 in both electrical and chemical coupling. A4 was electrically coupled to As2-4, with coupling between As2/3 and A4 being strongest and rectifying, in that hyperpolarizing current passed from A4 to As $2 / 3$ caused a larger postsynaptic voltage change than for the reverse (Fig. 7A1, Table 3). A4 made probable monosynaptic and reciprocal chemical excitatory connections with As1 (Fig. 7A2,A3) with no electrical component. The compound EPSPs induced by a train of $10-20$ spikes had amplitudes of $1-4 \mathrm{mV}(n=5)$, with a time to peak of 3-4 sec, and decayed over 10-20 sec.

In normal saline, the synaptic connection from A1 to A4 resembled that observed for As1-3 (Jing and Gillette, 1999), a biphasic early excitation followed by late inhibition (Fig. 7B) $(n=$ 14 of 15). These connections were abolished in high divalent saline and were likely to be polysynaptic. No connections from A4 to A1 were observed.

An A4 had similar connections with the contralateral As1-4 as with the ipsilateral: reciprocal chemical excitation with contralateral As1 and electrical coupling with As2-4 (Table 3). Electrical coupling was also observed between the bilateral A4 pair (coupling ratio, $\sim 0.1$ ), but because A4 axons do not cross to contralateral sides, coupling was probably made indirectly through the electrical connections to As2-4, axons of which run contralaterally (Jing and Gillette, 1999).

A finding of apparent significance to the mechanism of turning directionality was that an As1 also hyperpolarized and inhibited its contralateral A4 relatively strongly (Fig. 8), whereas inhibition of ipsilateral A4 was less strong and overridden by depolarization (compare Fig. 7A2). This inhibition was simultaneous with excitatory effects of As1 on both ipsilateral and contralateral A4 cells described above. The asymmetric inhibition of the A4 cells by single As1 neurons is consistent with a simple network model of avoidance turn directionality (see Discussion, Fig. 13). 

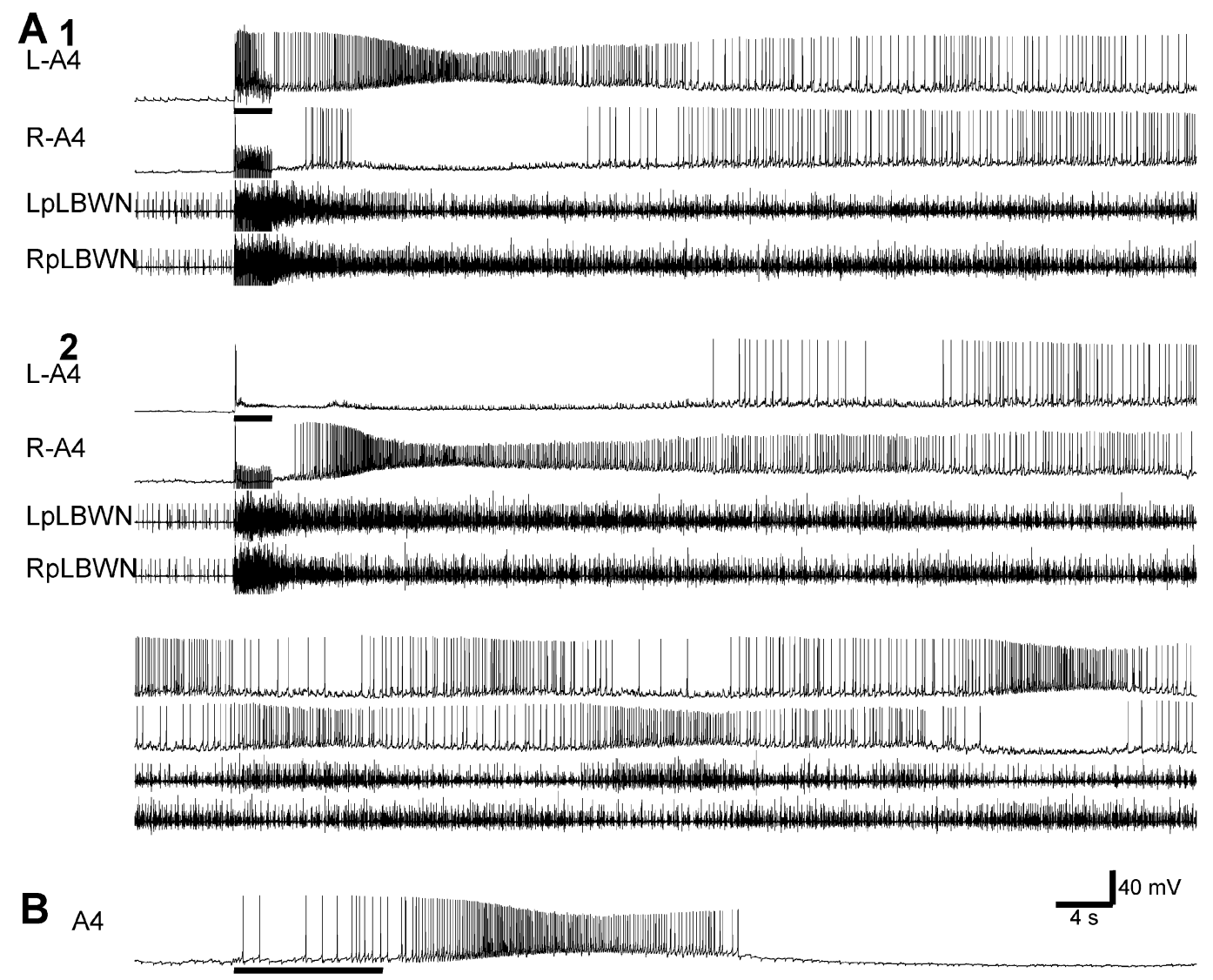

Figure 5. Asymmetric spiking activity of A4 interneurons during avoidance turns in isolated CNS and whole animals. $A$, In isolated CNS, shocks to left (A1) or right (A2) LOVN (bars) elicited fictive avoidance turns represented in strong motor activity in right pLBWN (RpLBWN, $A 7)$ and left pLBWN $(L P L B W N, A 2)$, respectively. The spike activity of left and right $A 4$ cells was directionally specific: the A4 ipsilateral to the stimulus was active whereas the contralateral $A 4$ was inactive. After the fictive turn, the A4 showed slow bursting activity in anti-phase to each other, corresponding to similar slow oscillation in the bilateral pLBWN (A2). Records of $A 1$ and $A 2$ are separated by $\sim 10$ min. Records in $A 2$ are continuous. $B$, In a whole-animal preparation, an $A 4$ fired a prolonged burst during an avoidance turn induced by mechanical stimulation of the ipsilateral oral veil (bar).

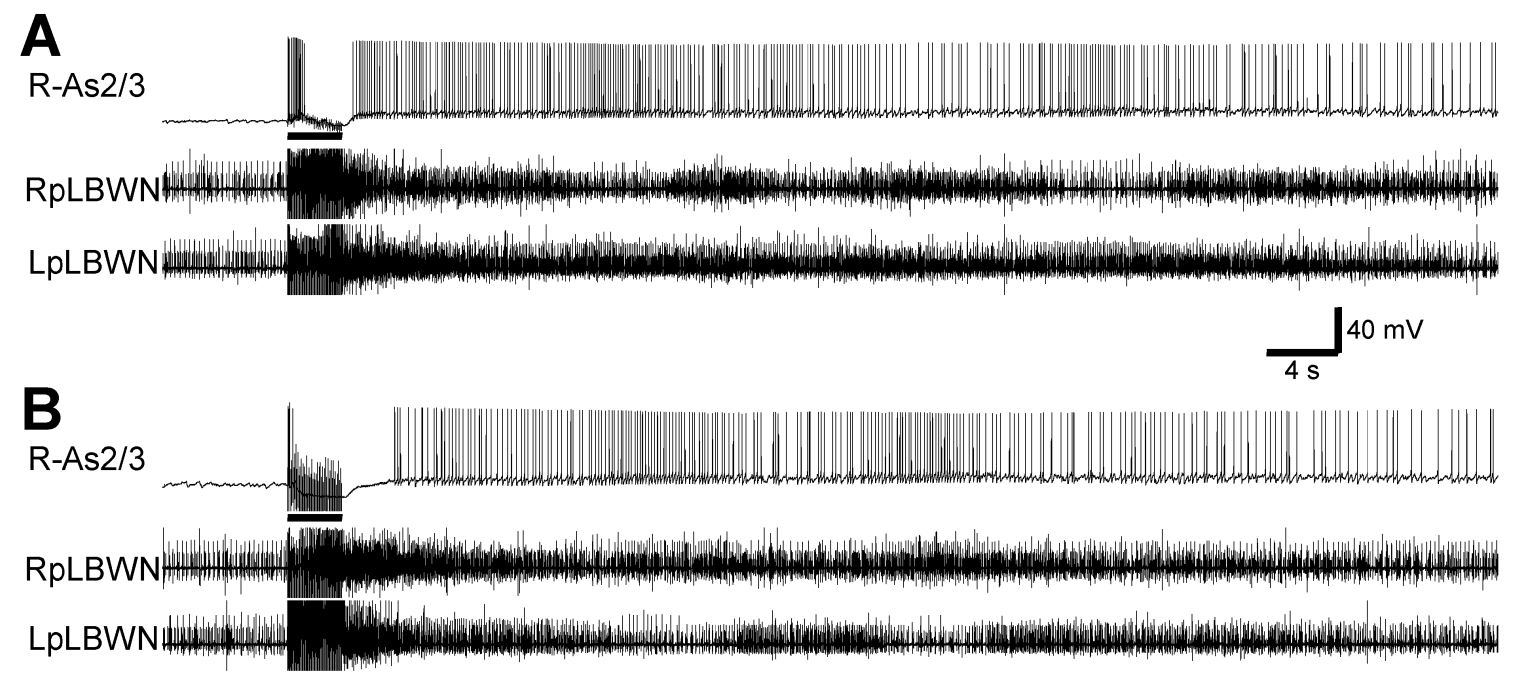

Figure 6. Directional sensitivity of As2/3 response to LOVN shock. $A$, Ipsilateral oral veil nerve stimulation (bar) induced short-latency firing $(0.6 \mathrm{sec})$ at moderate spike rate $(6-8 \mathrm{~Hz})$. $B$, Contralateral stimulation (bar) induced a response with longer latency ( $>3 \mathrm{sec}$ ) and lower frequency ( $3-5 \mathrm{~Hz}$ ). As1 also showed directional sensitivity to oral veil stimulation (see Results).

Roles of A4 and As1-3 in avoidance turning

We tested the requirements for A4 and As1-3 in avoidance turning by hyperpolarizing them to see whether turning motor output in the pLBWN was affected. Hyperpolarizing A4 had the most significant effects. In five experiments, turning motor out- put was nearly eliminated (Fig. 9). The brief burst of spikes in pLBWN during and immediately after LOVN stimulation, corresponding to the phase of withdrawal behavior, was unaffected by hyperpolarization of A4.

Hyperpolarization of As $2 / 3$ could also block fictive avoidance 
Table 2. Morphological and electrophysiological properties of A4 and A7: criteria for reidentification

\begin{tabular}{|c|c|c|c|c|c|c|c|}
\hline \multirow[b]{2}{*}{ Cell name } & \multirow[b]{2}{*}{ Axon path } & \multirow{2}{*}{$\begin{array}{l}\text { Cell size } \\
(\mu \mathrm{m}) ; \text { color }\end{array}$} & \multicolumn{3}{|c|}{ Electrophysiology } & \multirow{2}{*}{$\begin{array}{l}\text { Spontaneous spike and } \\
\text { PSPs activity }\end{array}$} & \multirow{2}{*}{$\begin{array}{l}\text { Activity during avoidance } \\
\text { turns induced by LOVN } \\
\text { stimulation }\end{array}$} \\
\hline & & & $\mathrm{RP}(\mathrm{mV})$ & $\mathrm{SH}(\mathrm{mV})$ & $\mathrm{SD}(\mathrm{mS})$ & & \\
\hline A4 & $\mathrm{i}-\mathrm{aCPC}$ & $\begin{array}{l}40-55 ; \\
\text { translucent }\end{array}$ & $-47.3 \pm 3.2$ & $80.6 \pm 6.4$ & 3.4 & $\begin{array}{c}2-4 \mathrm{~Hz}\left(80 \%{ }^{a}\right) \text {, slow } \\
\text { bursting } ; \text { IPSPs, } \\
<6 \mathrm{mV}(85 \%)\end{array}$ & $\begin{array}{l}\text { Only active (up to } 14 \mathrm{~Hz} \text { ) to } \\
\text { ipsilateral stimulus (note, } \\
\text { in contrast, As1-4 are } \\
\text { active to bilateral stimuli) }\end{array}$ \\
\hline A7 & $\mathrm{i}-\mathrm{aCPC}$ & $\begin{array}{l}35-50 ; \\
\text { translucent }\end{array}$ & $-45.9 \pm 4.5$ & $73.4 \pm 8.5$ & 3.6 & $\begin{array}{l}\text { Active at }<6 \mathrm{~Hz}(60 \%) ; \\
\text { IPSPs, } 1-7 \mathrm{mV}(95 \%)\end{array}$ & $\begin{array}{l}\text { Not active during turns, but } \\
\text { active during withdrawal } \\
\text { phase that occurs before } \\
\text { turns }\end{array}$ \\
\hline
\end{tabular}

Data are expressed as mean \pm SEM.

i-aCPC, Ipsilateral anterior cerebropedal connective; LOVN, large oral veil nerves; PSPs, postsynaptical potentials; BWN, body wall nerves; RP, resting potential; SH, spike height; SD, Spike duration at half amplitude. ${ }^{a}$ Percentage of preparations observed.

${ }^{b}$ Slow bursting has been observed previously in swim interneurons As2/3 (Jing and Gillette, 1999, their Table 1). Slow bursting in A4 has similar burst duration ( 40 sec), period ( $80-160$ sec) with that of As2/3, but typically has higher peak spike frequency (up to $11 \mathrm{~Hz}$ ).
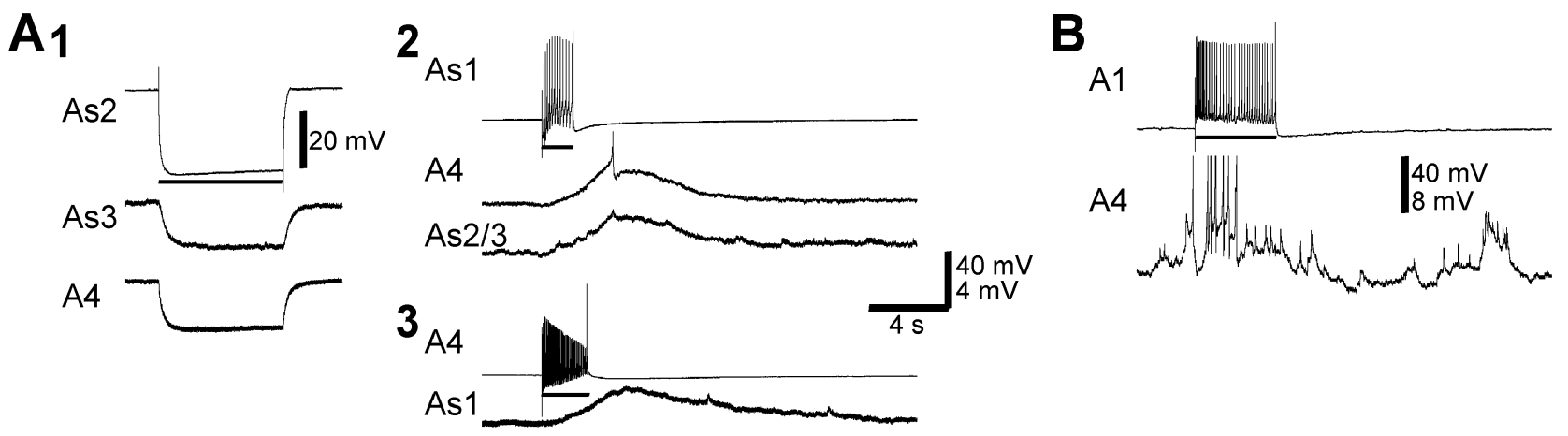

Figure 7. Synaptic connectivity of A4.A, Synaptic connections between A4 and the ipsilateral As1-3.A1, A4 was electrically coupled to As2 and As3 because A4 and As 3 were hyperpolarized when As2 was injected with a hyperpolarizing current (bar). As2 and As3 are indistinguishable, so name assignment for these two cells is arbitrary. A2, Depolarization of As1 (bar) to spike elicited slow EPSPs in A4 and As2/3. A3, Depolarization of A4 (bar) to spike elicited slow EPSPs in As1. All recordings were made in high divalent saline. B, Synaptic connections between A4 and the ipsilateral A1. Depolarization of A1 (bar) to spike induced biphasic effects in A4, an early excitation followed by inhibition. Spikes in A4 were clipped. Recordings were made in normal saline.

Table 3. Electrical coupling ratios (steady state) between A4 and ipsilateral or contralateral swim interneurons, As2-4

\begin{tabular}{llll}
\hline A4 & Ipsilateral As2/3 & Ipsilateral As4 & Contralateral As2/3 \\
\hline As a presynaptic cell & $0.185 \pm 0.012(29)$ & $0.111 \pm 0.021(3)$ & $0.161 \pm 0.04(4)$ \\
As a postsynaptic cell & $0.127 \pm 0.008(31)$ & $0.082 \pm 0.022(3)$ & $0.121 \pm 0.007(4)$ \\
\hline
\end{tabular}

Data are expressed as mean \pm SEM; number in parentheses indicates the number of measurements.

turning (Fig. 10). The effect may have been caused in part by the ability of As $2 / 3$ to hyperpolarize A4 through their electrical coupling. Figure $10 \mathrm{~B}$ shows an incident during the late phase of hyperpolarization of As2/3 when A4 escaped and fired a burst of $\sim 25 \mathrm{sec}$, restoring avoidance turn activity in contralateral pLBWN.

We tested the abilities of A4 and As1-3 to drive turning-like activity in pLBWN. A4 tended to drive higher activity in the pLBWN contralateral to its cell body (Fig. 11), similar to avoidance turns. A4 was driven at spike rates $14-21 \mathrm{~Hz}$ in these experiments, overlapping the frequencies observed in A4 during actual and fictive turns (average frequency calculated over 4-6 sec periods, 13-17 Hz) (Figs. 5, 9, 10). Of five A4 cells tested in five isolated CNS, four drove higher activity in the contralateral pLBWN, whereas one drove similar activity in pLBWN of both sides. The nerve activity was less prominent when spontaneously active A4 cells were driven. In two separate cases, A4 cells with high spontaneous activity failed to drive significant activity in either pLBWN, suggesting accommodation of a polysynaptic pathway.

Of the As1-3 group, As $2 / 3$ had the most significant effects on spike activity in pLBWN (Fig. 12 A). In $15 \mathrm{As} 2 / 3$ cells tested, 8 drove

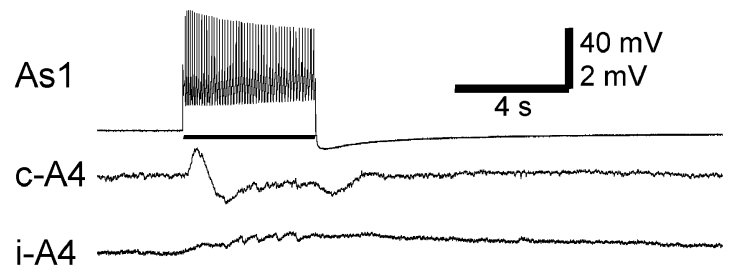

Figure 8. As1 strongly inhibits the contralateral A4. Driving an As1 with depolarizing current injection (bar) elicited depolarization in both ipsilateral and contralateral A4 (i-A4, c-A4), which was subsequently overridden by inhibition in the c-A4. Inhibition was slow, with occasional phasic IPSPs. Inhibitory potentials induced in i-A4 were less effectual. Recordings were made in high divalent saline.

highest activity in the ipsilateral pLBWN, 2 drove more activity in the contralateral nerve, 3 elicited similar activity in the bilateral nerves, and the remaining 2 were ineffective. In four experiments, the As1 neuron induced activity in both pLBWNs, with higher intensity in contralateral pLBWNs in two cases and in ipsilateral pLBWNs in the other two. In sum, the As cells tend to drive higher activity in ipsilateral pLBWNs, but the effects are variable.

When we examined the effects of driving the cells of the As1-3 ensemble on A4, we found that they had the capacity to induce activity resembling the prolonged burst of the avoidance command $(n=3)$. A brief $(<10 \mathrm{sec})$ stimulation of a single As $2 / 3$ induced prolonged bursting activity in the contralateral A4 with corresponding pLBWN activity contralateral to A4 (Fig. 12B). 


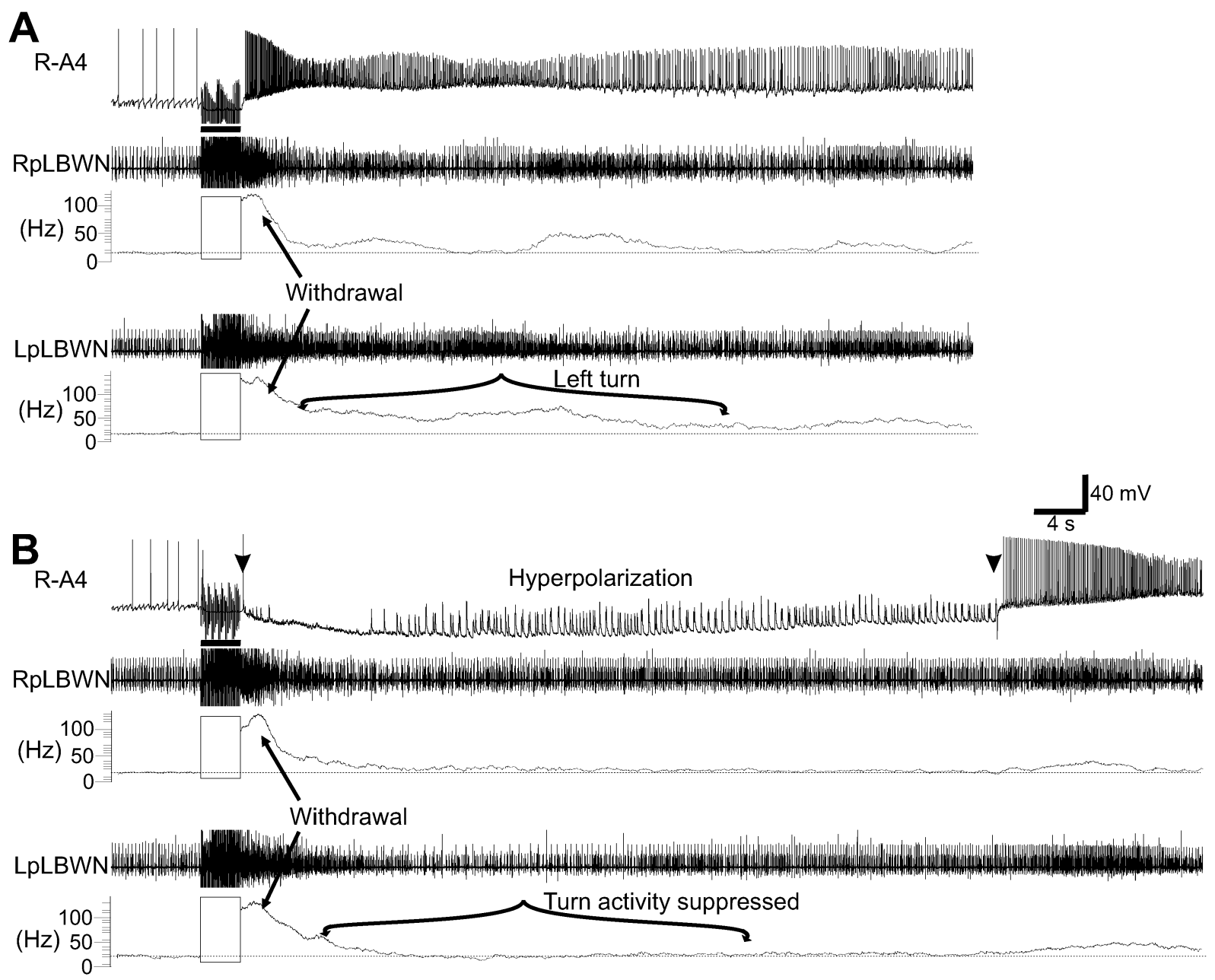

Figure 9. Hyperpolarization of A4 blocked fictive turning. $A$, Control. Fictive avoidance turning was elicited by brief electrical stimulation (bar) of the right $L O V N$, ipsilateral to the right $A 4$ ( $R$ - $A 4$ ). Fictive turning was evident in the prominent, long-lasting ( $>30 \mathrm{sec}$ ) activity in left posterior lateral body wall nerve ( $L p L B W N$; contralateral to $R$ - $A 4)$ ). Less activity was present in the right (ipsilateral) pLBWN (RpLBWN). B, Hyperpolarization of A4 (between arrowheads) after right LOVN stimulation suppressed the long-lasting activity in LpLBWN. The initial activity burst $(<10$ sec) immediately after LOVN stimulation in both LpLBWN and RpLBWN, presumed to represent head and anterior body withdrawal, was unaffected. Traces below nerve recordings are mean spike frequency plots (bin size, 1 sec). See Figure 3 legend for details.

Consequently, it is likely that the A4 cells are the primary interneurons that mediate avoidance turning behavior and that As1-4 sustain A4 activity during the turn by providing electrical and chemical excitation to A4.

\section{Discussion}

The avoidance turn of Pleurobranchaea, like the animal's escape swim, resembles a classic fixed-action pattern. It is specifically triggered by noxious stimuli, is stereotypic, and occurs in discrete episodes. Once triggered, the behavior proceeds through the entire sequence without further sensory inputs. Here, study of the genesis of the behavior has led to an enhanced view of neural network function in behavioral patterning and switching in this animal.

\section{Mechanisms of avoidance turning}

Lateral turns in soft-bodied animals with hydrostatic skeletons arise from bilateral control of longitudinal muscles, whereas circular or perpendicularly oriented muscles stabilize body length and diameter during bending (Kier and Smith, 1985; Kuenzi and Carew, 1994). We described distinct longitudinal muscle groups in Pleurobranchaea, in body wall and foot, including three prom- inent and symmetrical bands of lateral body wall muscle that mediate lateral avoidance turns.

A centrally patterned origin of avoidance turning was confirmed in semi-intact and completely deafferented preparations. The asymmetrical and prolonged motor activity recorded in the nerves ( $\mathrm{pLBWNs}$ ) after oral veil or LOVN shock was then used to identify the turning interneurons, the bilaterally paired A4 cells, and the As1- 4 cells.

The A4 neurons command the avoidance turn through spike activity necessary and sufficient to the behavior

The A4 cells were asymmetrically activated during a stimulated turn, and their prolonged activity closely corresponded to the turn duration $(20-40 \mathrm{sec})$. A unilateral noxious stimulus to the oral veil activated a prolonged burst in the ipsilateral A4, which drove contralateral bending of the body wall; the contralateral A4 was inhibited during the turn. Hyperpolarization of the ipsilateral cell blocked the turn.

The As1-4 neurons sustain the command

The serotonergic swim interneurons As1-4 are essential to avoidance turning by sustaining A4 activity and providing direc- 


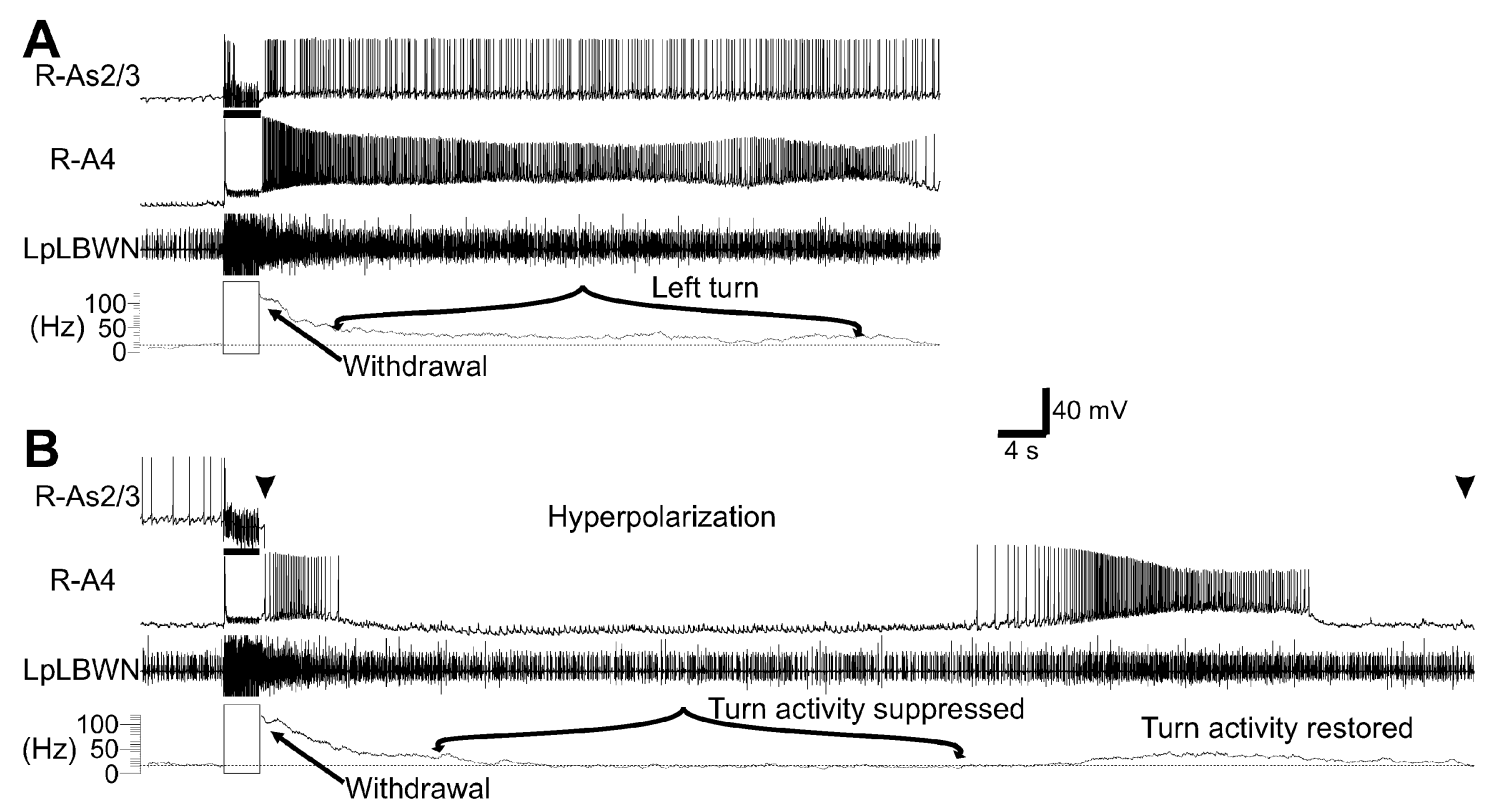

Figure 10. Role of As2/3 during avoidance turning. $A$, Stimulation of right LOVN (bar) activated both right As2/3 (R-As2/3) and right $A 4$ (R-A4) and strong output in left pLBWN (LPLBWN), indicative of an avoidance turn to the left. $B$, Hyperpolarization of As2/3 (arrowheads) suppressed fictive avoidance turning output in LpLBWN, until R-A4 escaped inhibition and fired a characteristic bursting that lasted $\sim 25 \mathrm{sec}$, when the turning activity was restored, at least partially, in LpLBWN. Traces below nerve recordings are mean spike frequency plots (bin size, 1 sec). See Figure 3 legend for details.

tionality of A4 activity. The cells of each As1-4 ensemble are coupled electrically and chemically to the A4 and can induce prolonged A4 activity when active. The directionality of A4 activity may be promoted by the As1 ipsilateral to A4, which is more active and elicits strong inhibition in the contralateral A4.

The primary function of As $2 / 3$ during turns may be to provide excitation to A4, whereas As1 essentially specifies the dominant and subordinate A4 sec. In quiescent preparations, an As2/3 could induce prolonged activity in the contralateral A4, whereas during induced turns the combined activity of the bilateral As 1-4 ensembles promoted activity of the ipsilateral A4. Although initiation of A4 activity by As $2 / 3$ is consistent with their role in sustaining A4 activity, the data suggest different functional roles for As $2 / 3$ and As1.

These observations and interpretations are summarized in a network model (Fig. 13), which both shows the known connectivity from which the concerted actions of A4 and As1-4 emerge and specifically predicts the existence of yet unidentified inhibitory neurons. In summary, the model posits that a noxious stimulus to one side of the head region activates the coupled A4 and As1-4 cells of the ipsilateral side of the cerebropleural ganglion that in turn drive inhibition of the contralateral A4. Activity of the ipsilateral A4 drives the motor neurons of the contralateral body wall muscle bands.

\section{Encoding of direction and angle of the avoidance turn: comparative aspects}

The avoidance turn of Pleurobranchaea is a directional escape response in which both event and directionality are determined by a winner-take-all outcome of activity in only a few neurons. In this, it resembles directional startle responses mediated by the Mauthner neurons of the fish (Eaton et al., 2001) and the lateral and medial giant neurons of the crayfish (Wine and Krasne, 1972; Edwards et al., 1999). However, the neural mechanisms are distinct in three respects. First, in contrast to fish and crayfish, Pleurobranchaea avoidance is apparently not served in parallel by
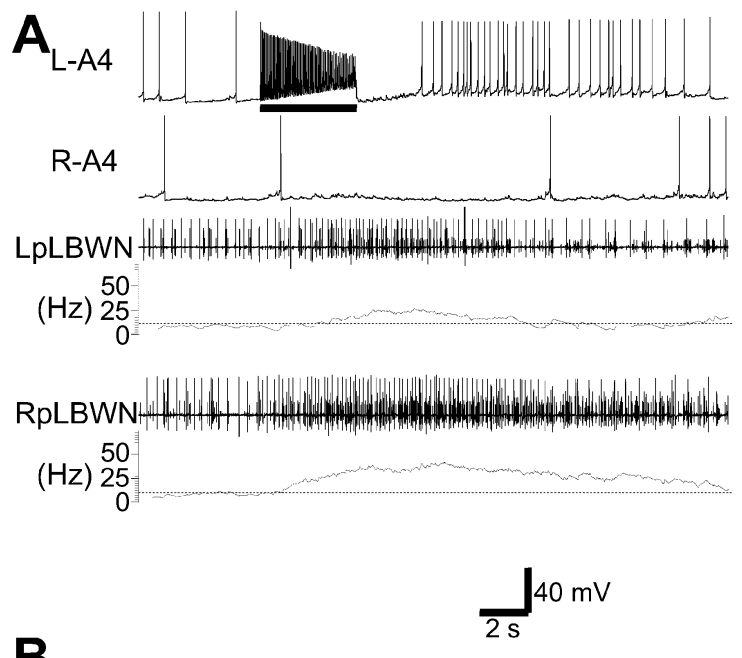

$\mathbf{B}_{\mathrm{L}-\mathrm{A} 4}$ $\underset{2 \mathrm{~s}}{ } 40 \mathrm{mV}$
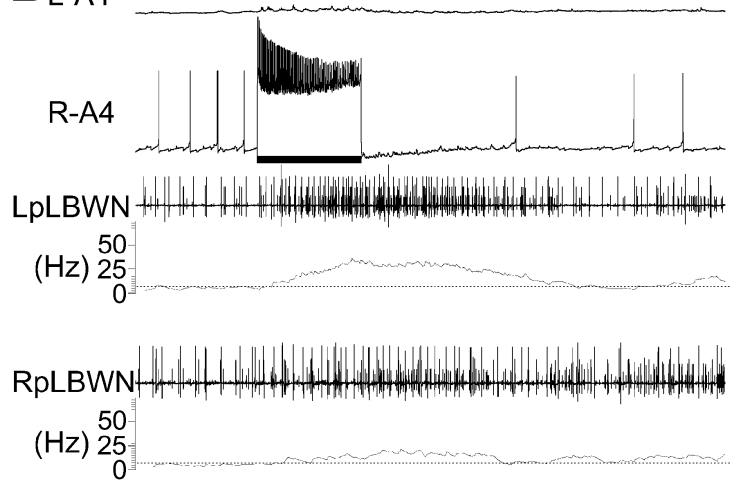

Figure 11. A4 drives fictive avoidance turning. Activation (bar) of the left $A 4(L-A 4)$ induced strong activity in right $\mathrm{pLBWN}(A, R p L B W N)$, suggesting a contralateral turn. Likewise, activation (bar) of the right $A 4(R-A 4)$ induced strong activity in left $p L B W N(B, L p L B W N)$. Traces below nerve recordings are mean spike frequency plots (bin size, $1 \mathrm{sec}$ ). See Figure 3 legend for details. 

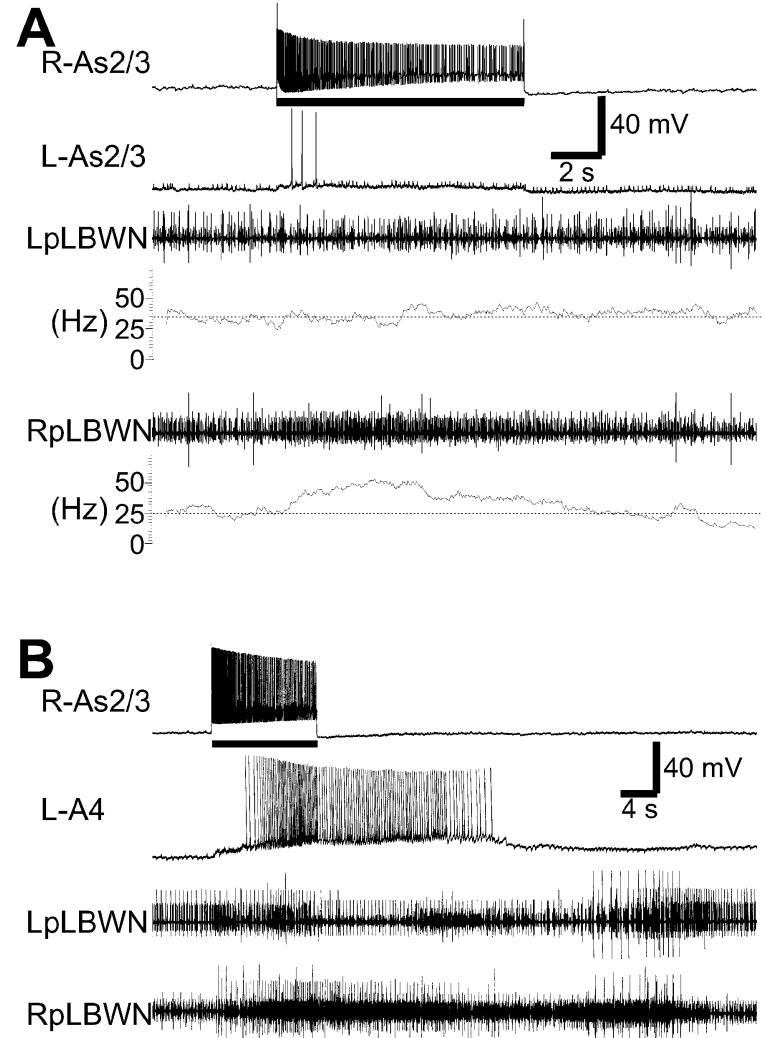

Figure 12. As $2 / 3$ activates $A 4$ and concomitant activity in $p L B W N$. $A$, Driving a right $A s 2 / 3$ $(R-A s 2 / 3$, bar) induced strong activity in the right, but not left, $\mathrm{pLBWN}$. Note that the left $A s 2 / 3$ $(L-A s 2 / 3)$ was not activated. Traces below nerve recordings are mean spike frequency plots (see details in Fig. 3 legend). $B$, In a different preparation, driving a right As2/3 (bar) induced a prolonged burst in the left $A 4$, with corresponding spike activity in right pLBWN.

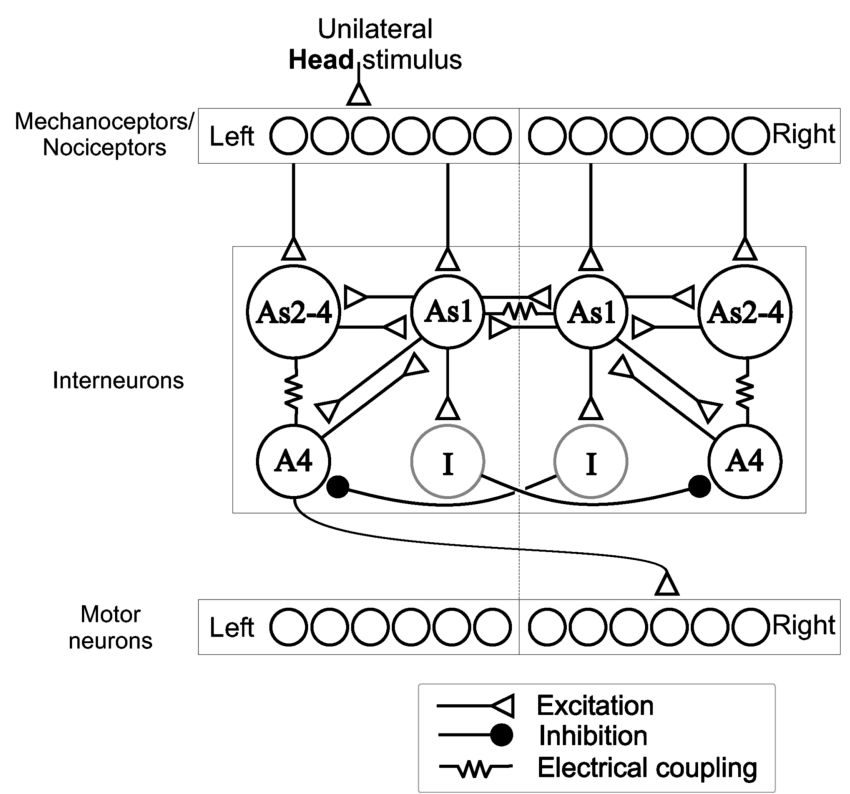

Figure 13. A network model for avoidance turning. In this model, appropriate sensory input is presumed to act on A4 and As1- 4 interneurons unilaterally. The prolonged A4 burst of the turn is initiated and sustained by reverberating excitation among As1-4 and A4 neurons. Inhibition of the contralateral A4 is mediated by a hypothetical inhibitory neuron (I) primarily excited by As1 (Fig. 8). A4 would also excite the "I" neuron through its excitation to As1-4, if not directly as well. Potentially, the I neuron might also be activated by unilateral sensory inputs (not shown). Finally, A4 excites the contralateral turning motor neurons to cause a contralateral turn.

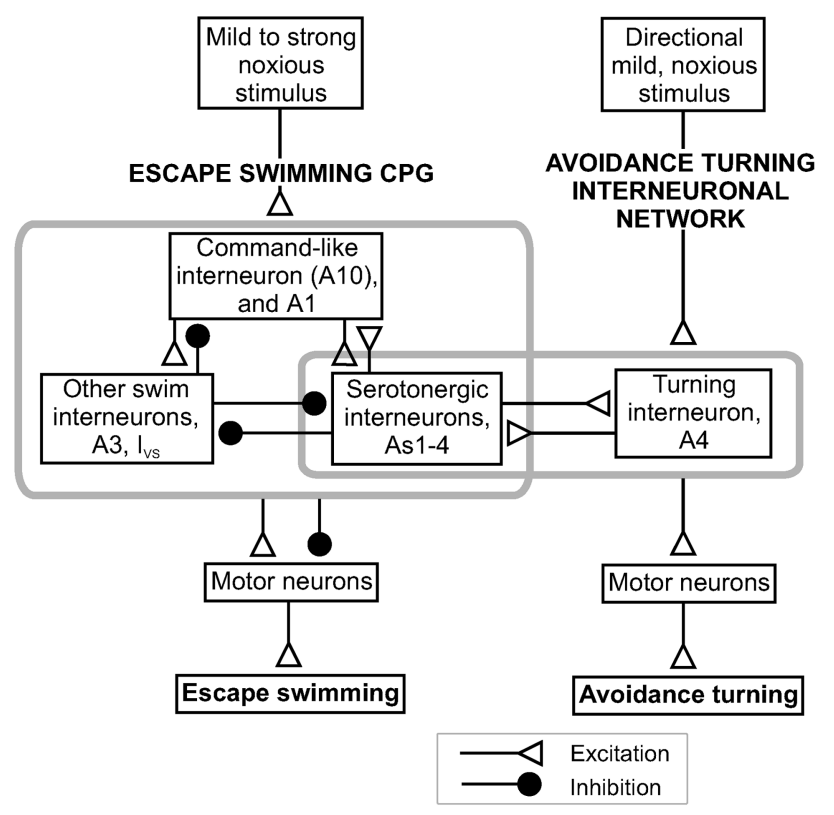

Figure 14. A network model for behavioral choice between avoidance turning and escape swimming, based on state transition in neural networks by cooption of motive elements. As 1-4 provide the driving excitation in both the avoidance turning (the avoidance turning interneuron A4) and the escape swimming (PG (Jing and Gillette, 1999) (the A1/A10 ensemble). Noxious stimulation of the head primarily excites As1-4. At moderate levels of As1-4 activity, the avoidance network formed by A4/As1 -4 is expressed. At higher levels of excitation and stronger activation of As1-4, the A1/A10 ensemble is recruited to form the operational swim network, which then coopts As1- 4 into rhythmic burst activity phase-locked to the swim cycle. Cyclic excitation and inhibition of A4 by swim interneurons during the swim prevents the prolonged A4 burst and thereby suppresses avoidance turning. As1-driven inhibition from the hypothetical inhibitory neurons of the avoidance turning network (Fig. 8) may also contribute. $I_{V s}$ Ventral swim interneuron.

other, less specialized interneurons that contribute to components of the overall behavior. Second, where escape in fish and crayfish is a ballistic action of fractions of a second triggered by a single or few action potentials in Mauthner cell or giant fibers, A4-driven avoidance turning is 1000-fold longer in duration and driven by a prolonged train of spikes. The A4 analog of the few commanding spikes of giant cells of fish and crayfish is the prolonged depolarization of the burst. Like negative phonotaxis of cricket mediated by a sensory interneuron (Nolen and Hoy, 1984; Hoy, 1989), both directionality and duration of the avoidance behavior are set by a single neuron.

Third, it appears likely that both direction and angle of the avoidance turn are encoded in the burst in a single A4, because (1) driving an A4 at spike rates observed during the actual and fictive turn produced appropriate motor activity and (2) silencing an A4 did not merely alter turn direction or amplitude but entirely nullified the turn. Thus, A4 is the major, and probably only, final determinant of the turning command. This contrasts with other directional behaviors in which the turn angle may be a function of activity in multiple neurons. In these, direction angle is a "population vector" integrated from activities of multiple neurons (for review, see Grillner et al., 1997; Sparks et al., 1997). These include cockroach escape turns (Ritzmann, 1993; Levi and Camhi, 2000; Comer and Robertson, 2001), leech bending (Lockery and Kristan, 1990; Lewis and Kristan, 1998), primate saccadic eye movements (Lee et al., 1988), and perhaps primate reaching (Georgopoulos et al., 1986). The reason for this difference may lie in a greater need for both spatial and temporal precision in mus- 
cle group coordination in arthropod, annelid, and primate for the "targeted" nature of the population vector responses, as opposed to the simpler temporal simultaneity and only broad directionality required of molluscan muscle bands in the avoidance turn.

\section{Behavioral choice: avoidance turn or escape swim}

How is avoidance behavior integrated into Pleurobranchaea's behavioral repertory at the neural network level? Avoidance turning is interrupted and suppressed by expression of both active feeding (Gillette et al., 2000) and escape swimming (Jing and Gillette, 1999). We speculate that avoidance turning is suppressed by feeding network activity through the same or similar corollary output paths shown previously to suppress reflex withdrawal from tactile stimuli during feeding (Kovac and Davis, 1980).

The suppression of the avoidance turn by the escape swim may represent a novel type of behavioral switch, however, in which elements providing the intrinsic network excitation of the pattern generator for one behavior (turning) can be effectively assimilated by the pattern generator for the other (swimming). Thus, when the As1-4 neurons are recruited into the swim oscillator, the A4 cells are phase-locked into weak cyclic activity with the swim and thereby prevented from the tonic unilateral discharge necessary to avoidance turns.

These data suggest a network model (Fig. 14) for the decision between expression of escape swimming and the avoidance turn. The decision mechanism may incorporate a neural network switch regulated by stimulus intensity in which the level of As1-4 activity induced determines behavioral expression. Swimming is a higher threshold avoidance behavior than the turn, and the critical factor that recruits A1/A10 is related to the strength of the As1-4 response to noxious stimuli. The As1-4 spike frequencies recorded during avoidance turns were only approximately half those during the swim (Jing and Gillette, 1999). We hypothesize that activation of the A1/A10 ensemble of the swim network at the high spike rates typical of the swim motor pattern initiates the swim and coopts the As1-4 into the active swim network. The prolonged burst of the A4 cells that drives the avoidance turn is interrupted and suppressed by the cyclic excitation/inhibition of As1-4 in the swim oscillator, dedicating behavioral expression to swimming. Otherwise, at low stimulus intensities, a moderate and asymmetric As1-4 response sustains avoidance turning.

\section{Multifunctionality of the As1-4 neurons}

The serotonergic As1-4 show marked evolutionary conservation in gastropods, along with critical and multifunctional roles in central neural networks. We speculate that these neurons have been important organizing elements of CNS function around which the broad diversification in morphology, niche, and behavior of these molluscs has occurred. The As1-4 are evolutionarily highly conserved neurons, the presence of which has been demonstrated in the CNS of very disparate species of opisthobranch and pulmonate gastropods (Sudlow et al., 1998). In Pleurobranchaea, As1-4 were known to provide the intrinsic neuromodulatory excitation to the swim CPG that sustains the escape swim episode through multiple cycles (Jing and Gillette, 1999), as do the homologous DSI cells of Tritonia (Lennard et al., 1980; Katz and Frost, 1997). Also in Pleurobranchaea, As1-4 were found to exert a general stimulatory role in the distributed serotonergic arousal network of the mollusk, including other modulatory and serotonergic cells in both feeding and locomotor networks (Jing and Gillette, 2000). As well, in Aplysia, a likely As4 homolog heterosynaptically facilitates the gill-siphon withdrawal circuit (Mackey et al., 1989) and excites the serotonergic heart excitor (Xin et al., 2001). Probable As1-4 homologs in Clione provide premotor neuromodulatory excitation of the locomotor cells (Satterlie and Norekian, 1996; Orlovsky et al., 1999). In Tritonia, the As1-4 homologs have other roles in reflexive withdrawal (Getting and Dekin, 1985) and in driving locomotion, where they activate locomotion at low levels of activity and escape swimming at higher (Popescu and Frost, 2002), similar to their function in release of avoidance turning versus the swim in Pleurobranchaea.

The present findings, that As1-4 also have prominent roles in avoidance turning, indicate that they are critical, multifunctional components on which much of the organization of the animal's behavior rests. These results make it appear likely that the As1-4 and their homologs in other gastropods have similar broad and pivotal roles in the partitioning of behavior.

Thus, the avoidance turn is a centrally patterned, stereotypic response mediated by a small neural network organized around the bilateral A4 interneuron pair, the asymmetric activity of which may encode both turn direction and amplitude. The A4 command is sustained by activity in the As1-4 cells, which also have critical roles in other, metastable, neural networks in both gating and sustaining expression of quite dissimilar behaviors. The better understanding of the neural basis of avoidance turning in this animal may enable future studies of mechanisms through which learning and internal state influence the decision between orienting and avoidance turns in foraging behavior.

\section{References}

Bablanian GM, Weiss KR, Kupfermann I (1987) Motor control of the appetitive phase of feeding behavior in Aplysia. Behav Neural Biol 48:394-407.

Brace RC (1977a) Shell attachment and associated musculature in the Notaspidea and Anaspidea (Gastropoda: Opisthobranchia). Trans Zool Soc Lond 34:31-42.

Brace RC (1977b) The functional anatomy of the mantle complex and columellar muscle of tectibranch molluscs (Gastropoda: Opisthobranchia), and its bearing on the evolution of opisthobranch organization. Philos Trans R Soc Lond B Biol Sci 277:1-54.

Comer CM, Robertson RM (2001) Identified nerve cells and insect behavior. Prog Neurobiol 63:409-439.

Cook DG, Carew TJ (1989) Operant conditioning of head-waving in Aplysia. I. Identified muscles involved in the operant response. J Neurosci 9:3097-3106.

Davis WJ, Siegler MVS, Mpitsos GJ (1973) Distributed neuronal oscillators and efference copy in the feeding system of Pleurobranchaea. J Neurophysiol 36:258-274.

Eaton RC, Lee RK, Foreman MB (2001) The Mauthner cell and other identified neurons of the brainstem escape network of fish. Prog Neurobiol 63:467-485.

Edwards DH, Heitler WJ, Krasne FB (1999) Fifty years of a command neuron: the neurobiology of escape behavior in the crayfish. Trends Neurosci 22:153-161.

Georgopoulos AP, Schwartz AB, Kettner RE (1986) Neuronal population coding of movement direction. Science 233:1416-1419.

Getting PA, Dekin MS (1985) Mechanisms of pattern generation underlying swimming in Tritonia. IV. Gating of central pattern generator. J Neurophysiol 53:466-480.

Gillette R, Saeki M, Huang R-C (1991) Defense mechanisms in notaspidean snails: acid humor and evasiveness. J Exp Biol 156:335-347.

Gillette R, Huang RC, Hatcher N, Moroz LL (2000) Cost-benefit analysis potential in feeding behavior of a predatory snail by integration of hunger, taste, and pain. Proc Natl Acad Sci USA 97:3585-3590.

Grillner S, Georgopoulos AP, Jordan LM (1997) Selection and initiation of motor behavior. In: Neurons, networks, and motor behavior (Stein PS, Grillner S, Selverston AI, Stuart DG, eds), pp 1-19. Cambridge, MA: MIT.

Hoy RR (1989) Startle, categorical response, and attention in acoustic behavior of insects. Annu Rev Neurosci 12:355-375.

Jing J (1998) Interacting premotor networks mediating behavioral selection 
in the predatory marine snail Pleurobranchaea californica. PhD dissertation, University of Illinois.

Jing J, Gillette R (1995) Neuronal elements that mediate escape swimming and suppress feeding behavior in the predatory sea slug Pleurobranchaea. J Neurophysiol 74:1900-1910.

Jing J, Gillette R (1996) Turning behavior in the predatory sea slug Pleurobranchaea: functional anatomy and neural mechanisms. Soc Neurosci Abstr 22:1404.

Jing J, Gillette R (1999) Central pattern generator for escape swimming in the notaspid sea slug Pleurobranchaea californica. J Neurophysiol 81:654-667.

Jing J, Gillette R (2000) Escape swim network interneurons have diverse roles in behavioral switching and putative arousal in Pleurobranchaea. J Neurophysiol 83:1346-1355.

Katz PS, Frost WN (1997) Removal of spike frequency adaptation via neuromodulation intrinsic to the Tritonia escape swim central pattern generator. J Neurosci 17:7703-7713.

Kier WM, Smith KK (1985) Tongues, tentacles and trunks: the biomechanics of movement in muscular-hydrostats. Zool J Linn Soc 83:307-324.

Kovac MP, Davis WJ (1980) Neural mechanism underlying behavioral choice in Pleurobranchaea. J Neurophysiol 43:469-487.

Kuenzi FM, Carew TJ (1994) Head waving in Aplysia californica. II. Functional anatomy and muscular activity during behaviour. J Exp Biol 195:53-74.

Lee C, Rohrer WH, Sparks DL (1988) Population coding of saccadic eye movements by neurons in the superior colliculus. Nature 332:357-360.

Lee RM, Liegeois RJ (1974) Motor and sensory mechanism of feeding in Pleurobranchaea. J Neurobiol 5:545-564.

Lennard PR, Getting PA, Hume RI (1980) Central pattern generator mediating swimming in Tritonia. II. Initiation, maintenance, and termination. J Neurophysiol 44:165-173.

Levi R, Camhi JM (2000) Wind direction coding in the cockroach escape response: winner does not take all. J Neurosci 20:3814-3821.

Lewis JE, Kristan WB Jr (1998) Quantitative analysis of a directed behavior in the medicinal leech: implications for organizing motor output. J Neurosci 18:1571-1582.

Lockery SR, Kristan WB Jr (1990) Distributed processing of sensory information in the leech. II. Identification of interneurons contributing to the local bending reflex. J Neurosci 10:1816-1829.

London JA, Gillette R (1984) Functional roles and circuitry in an inhibitory pathway to feeding command neurones in Pleurobranchaea. J Exp Biol 113:423-446.

Mackey SL, Kandel ER, Hawkins RD (1989) Identified serotonergic neurons LCB1 and RCB1 in the cerebral ganglia of Aplysia produce presynaptic facilitation of siphon sensory neurons. J Neurosci 9:4227-4235.

Mpitsos GJ, Davis WJ (1973) Learning: classical and avoidance conditioning in the mollusk Pleurobranchaea. Science 180:317-320.

Mpitsos GJ, Collins SD (1975) Learning: rapid aversive conditioning in the gastropod mollusk Pleurobranchaea. Science 188:954-957.

Nolen TG, Hoy RR (1984) Initiation of behavior by single neurons: the role of behavioral context. Science 226:992-994.

Orlovsky GN, Deliagina TG, Grillner S (1999) Neural control of locomotion. New York: Oxford UP.

Popescu IR, Frost WN (2002) Highly dissimilar behaviors mediated by a multifunctional network in the marine mollusk Tritonia diomedea. J Neurosci 22:1985-1993.

Ritzmann RE (1993) The neural organization of cockroach escape and its role in context-dependent orientation. In: Biological neural networks in invertebrates: neuroethology and robotics (Beer RD, Ritzmann RE, Mckenna T, eds), pp 113-137. San Diego: Academic.

Satterlie RA, Norekian TP (1996) Modulation of swimming speed in the pteropod mollusc, Clione limacina: role of a compartmental serotonergic system. Invert Neurosci 2:157-165.

Sparks DL, Kristan WB, Shaw BK (1997) The role of population coding in the control of movement. In: Neurons, networks, and motor behavior (Stein PS, Grillner S, Selverston AI, Stuart DG, eds), pp 21-32. Cambridge, MA: MIT.

Sudlow LC, Jing J, Moroz LL, Gillette R (1998) Serotonin-immunoreactivity in the central nervous system of the marine molluscs Pleurobranchaea californica and Tritonia diomedea. J Comp Neurol 395:466-480.

Teyke T, Weiss KR, Kupfermann I (1990) Appetitive feeding behavior of Aplysia: behavioral and neural analysis of directed head turning. J Neurosci 10:3922-3934.

Walters ET, Erickson MT (1986) Directional control and the functional organization of defensive responses in Aplysia. J Comp Physiol [A] 159:339-351.

Wine JJ, Krasne FB (1972) The organization of the escape behavior in the crayfish. J Exp Biol 56:1-18.

Xin Y, Koester J, Jing J, Weiss KR, Kupfermann I (2001) Cerebralabdominal interganglionic coordinating neurons in Aplysia. J Neurophysiol 85:174-186. 